
студентов к условиям обучения в вузе

Боденова О.В. ${ }^{1, a}$, Власова Л.П. ${ }^{2, b}$

${ }^{1}$ Институт педагогики и психологии ФГБОУ ВО «Петрозаводский государственный университет», Петрозаводск, Российская Федерация.

2ФГБОУ ВО «Петрозаводский государственный университет»,

Петрозаводск, Российская Федерация.

a iD ORCID: https://orcid.org/0000-0002-8655-8712, e-mail: lazarewaol-ga@yandex.ru

b(iD ORCID: https://orcid.org/0000-0003-0926-6318, e-mail: vnmvim1423@yandex.ru

Резюме: Статья посвящена обзору одной из наиболее актуальных проблем, возникающих в процессе сопровождения адаптации обучающихся. В работе раскрывается содержание процесса адаптации, ее содержательных и процессуальных характеристик, описываются виды и этапы, направления диагностики.

Целью работы является выявление особенностей адаптации у студентов-первокурсников, в том числе описание специфики трудностей адаптации иногородних студентов.

Исследование проводилось в Институте педагогики и психологии ПетрГУ со студентами первых курсов, обучающимися по направлению подготовки 44.03.02 Психолого-педагогическое образование, 44.03.01. Педагогическое образование, 44.03.03 Специальное (дефектологическое) образование.

Для проверки гипотезы применялись опросные методы - методика анкетирования «Я студент», методика «Шкала субъективного благополучия», метод анализа документов (анализ медицинских карт обучающихся), количественный и качественный анализ.

Результаты исследования. Анализ результатов исследования показал, что у иногородних студентов возникают как общие, так и специфические трудности адаптации, обусловленные разрывом прежних родственных и дружеских отношений, отсутствием эмоциональной поддержки, тяжелыми бытовыми условиям, новым соседством, новым типом поселения и др. Полученные результаты применяются для разработки и реализации мероприятий по поддержке обучающихся в период адаптации.

Ключевые слова: адаптация, дезадаптация, трудности адаптации, сопровождение адаптации.

Для цитирования: Боденова О.В. Особенности адаптации иногородних студентов к условиям обучения в вузе / О.В. Боденова, Л.П. Власова // Развитие образования. - 2020. - № 4 (10). - С. 53-58. DOI:10.31483/r-96296.

\title{
Features of Adaptation of Non-Resident Students to the University Learning Environment
}

\author{
Olga V. Bodenova ${ }^{1, a}$, Lyudmila P. Vlasova ${ }^{2, b}$ \\ Institute of Pedagogy and Psychology of FSBEI of HE "Petrozavodsk State University", \\ Petrozavodsk, Russian Federation. ${ }^{1}$ \\ FSBEl of HE "Petrozavodsk state University", \\ Petrozavodsk, Russian Federation. ${ }^{2}$ \\ ID ORCID: https://orcid.org/0000-0002-8655-8712, e-mail: lazarewaol-ga@yandex.ru \\ b iD ORCID: https://orcid.org/0000-0003-0926-6318, e-mail: vnmvim1423@yandex.ru
}

\begin{abstract}
The article is devoted to the overview of one of the most current problems that arise in the process of supporting the adaptation of students. The paper reveals the content of the adaptation process, its content and procedural characteristics, describes the types and stages, and directions of diagnostics.

The aim of the work is to identify the features of adaptation in first-year students, including the description of the specifics of difficulties of non-resident students' adaption.

The study was conducted at the Institute of Pedagogy and Psychology "Petrozavodsk State University" with first-year students studying in the fields of education 44.03.02 Psychological and pedagogical education, 44.03.01. Pedagogical education, 44.03.03 Special (defectologic) education.

The following methods were used to test the hypothesis: "I am a student» survey, "Scale of subjective well-being» method, analysis of documents (medical records of students), quantitative and qualitative analysis.

The results of the study. Analysis of the results of the study showed that non-resident students have both general and specific difficulties of adaptation due to the breakdown of previous family and friendships, lack of emotional support, difficult living conditions, a new neighborhood, a new type of settlement, etc. The obtained results are used for development and implementation of measures to support students during the adaptation period.
\end{abstract}

Keywords: adaptation, disadaptation, difficulties of adaptation, support of adaptation.

For citation: Bodenova O.V., \& Vlasova L.P. (2020). Features of Adaptation of Non-Resident Students to the University Learning Environment. Razvitie obrazovaniya = Development of education, 4(10), 53-58. (In Russ.) DOI:10.31483/r-96296. 


\section{Урӑх хуларан килнӗ студентсем аслӑ шкулта вӗренме хӑнӑхнин уйрӑмлӑхӗсем}

Боденова О.В.,

'Педагогика тата психологи институчӗ $\mathrm{AB}$ «Петрозаводск патшалӑх университечӗ» ФПБВУ,

Петрозаводск, Рас̧с̧ей Федерацийӗ.

${ }^{2} \mathrm{AB}$ «Петрозаводск патшалӑх университечӗ» ФПБВУ ,

Петрозаводск, Рас̧с̧ей Федерацийӗ.

a(D) ORCID: https://orcid.org/0000-0002-8655-8712, e-mail: lazarewaol-ga@yandex.ru

b(D) ORCID: https://orcid.org/0000-0003-0926-6318, e-mail: vnmvim1423@yandex.ru

Аннотаци: Статьяра сӑмах вӗренме килнисене с̧ӗнӗ лару-тӑрӑва хӑнӑхтарассипе с̧ыхӑннӑ пӗр паян куншӑн чи пӗлтерӗшлӗ те йывӑр ыйту пирки пырать. Ӗс̧ре адаптаци процесӗн содержанине, унӑн тытӑмӗпе ӗс̧не-хӗлне ӑнлантаракан характеристикине ус̧ӑмлӑ тунӑ, дагностикин тӗсӗсесемпе тапхӑрӗсене, суул-йӗрне кӑтартнӑ.

Ӗс̧ӗн тӗллевӗ пӗрремӗш курсра вӗренекен студентсен хӑнӑху уйрӑмлахӗсене тупасси, вӑл шутра урӑх с̧ӗртен килнӗ студентсен хӑнӑхупа с̧ыхӑннӑ йывӑрлӑхӗн хӑй енлӗхне кӑтартасси, пулса тӑрать.

Тӗпчеве Петрозаваодск патшалӑх университечӗн Педагогикӑпа психологи Институтӗнче 44.03 .02 (Психологипе педагогика пӗлӗвӗ), 44.03.01 (Педагогика пӗлӗвӗ), 44.03.03 (Ятарлӑ (дефектологи) пӗлӗвӗ) направленисемпе вӗренекен пӗрремӗш курс студенчӗсемпе ирттернӗ.

Гипотезӑна тӗрӗслеме ыйтӑм меслечӗсемпе уса курнӑ - «Эпӗ студент» анкетировани методикипе, «Субъективлӑх ырлӑхӗн шкали» методикипе, документсене тишкернипе (вӗренекенсен медицина карттисене пӑхса тухнӑ), хисеппе пахалӑх тишкерӗвӗпе.

Тӗпчев результачӗсем. Тӗпчевӗн результачӗсене тишкерни ак мӗн кӑтартрӗ: урӑх с̧ӗртен килнӗ студентсен хӑнӑхӑвӗнче пӗтӗм йышра тата уйрӑм с̧ынра унчченхи тӑванлӑх тата юлташлӑх с̧ыхӑнӑвӗсем татӑлнипе, кӑмӑл-туйӑм енчен хавахалантару с̧уккипе, кил терёшӗнче хӑтлӑх с̧уккипе, палламан с̧ынсемпе ку๊ршӗллӗ пурӑннипе, урӑхла йышши с̧уртра пурӑннипе с̧уралнӑ йывӑрлӑхсем пулас̧с̧ӗ. Тӗпчев результачӗсемпе эпир студентсене хӑнӑху тапхӑрӗнче пулӑшма май паракан мероприятисене хатӗрлеме тата ирттерме усӑ куратпӑр.

Tӗп сӑмахсем: хӑнӑху (адаптаци), хӑнӑхӑва с̧ухатни (дезадаптаци), хӑнӑху йывӑрлӑхӗсем, хӑнӑхӑва ертсе (пулӑшса) пыни.

Цитатӑлама: Боденова О.В. Урӑх хуларан килнӗ студентсем аслӑ шкулта вӗренме хӑнӑхнин уйрӑмлӑхӗсем / О.В. Боденова, Л.П. Власова // Вӗренў аталанӑве̌. - 2020. - № 4 (10). - С. 53-58. DOI:10.31483/r-96296.

\section{Актуальность}

В настоящее время особое место в гуманитарных, естественных науках занимают исследования проблем адаптации студенчества к условиям профессионального обучения. Данная тенденция объясняется, с одной стороны, возрастанием динамичности развития различных институтов социализации, возрастанием когнитивной и эмоциональной сложности факторов и условий адаптации, нормативных требований образовательных организаций, а с другой стороны, снижением адаптивного потенциала обучающихся, препятствующего активизации и развитию адаптивных стратегий поведения.

Обзор литературы показывает, что студенчество, с одной стороны, обладает потенциалом, обеспечивающим быструю, безболезненную адаптацию к новым условиям (Н.Н. Мельникова, Л.В. Шабанов, И.Л. Шелехов, Е.В. Мороденко и др.). Но, с другой стороны, без специальных адаптационных мероприятий значительная часть обучающихся может испытывать значительные трудности, приводящие в некоторых случаях к отказу от получения профессионального образования. При этом становится очевидным, что группой риска по дезадаптации в большинстве случаев становятся иногородние студенты, в силу наличия факторов, отягчающих адаптацию. Поэтому для организации эффективного сопровождения адаптационного процесса требуется глубокое изучение процессуальных и результативных характеристик адаптации обучающихся.

\section{Разработанность темы}

Обзор имеющихся подходов к определению понятия «адаптация» позволяет сделать вывод, что ее суть заключается в выработке приспособительных реакций, требующегося поведения к новым условиям среды на физиологическом, социальном, психологическом уровнях функционирования личности [1, с. 5]. В данной работе адаптация обучающихся к условиям обучения рассматривается как восприятие, понимание, усвоение стандартов поведения, ценностных ориентаций, новой социальной группы, сближение установок, направленности адаптирующейся личности с ожиданиями новой социальной среды.

Результатом адаптации студентов должно стать такое состояние взаимоотношений с группой, при котором обучающийся без затяжных, острых внутриличностных и межличностных конфликтов осваивает содержание учебной деятельности, удовлетворяет потребности в общении, самоактуализации, принимает и следует нормам образовательной организации [4, с. 76]. Таким образом, состояние адаптированности студента можно определить как усвоение и адекватное выполнение новой социальной роли.

Традиционно в структуре адаптации студентов выделяются следующие компоненты:

1) физиологическая долговременная адаптация, направленная на постепенное привыкание организма к действию новых раздражителей. В вузе такими раздражителями являются новый режим дня, сокращение времени на отдых, изменение питания, климата, условий проживанияи т. д.;

2) социальная адаптация, которая направлена на освоение новой социальной роли, включающей определенное поведение, нормы поведения, учебной деятельности, санкции за их нарушение или соблюдение; 
3) психологическая адаптация, направленная на достижение психологического благополучия, эмоционального комфорта, признание и уважение в группе;

4) академическая адаптация или приспособление к новым условиям обучения в вузе - новые формы организации занятий, самостоятельной работы, необходимость работать снаучным литературой и т. д.;

5) профессиональная адаптация, проявляющаяся в принятии выбранной

профессии, в постепенном развитии профессионального самосознания;

6) бытовая адаптация - создание собственного быта;

7) средовая адаптация - освоение новой территории;

Перечисленные аспекты адаптации взаимосвязаны и оказывают определенное влияние другна друга.

Как правило, привыкание к новым условиям длится 3-4 недели и имеет три этапа: ориентировочный этап, этап неустойчивой адаптации и этап истинной адаптации [1, с. 10]. В течение адаптационного периода следует изучать динамику эмоционального, физического, психологического и социальнопсихологического благополучия обучающихся. Предметом изучения адаптации может являться уровень адаптированности в настоящий момент, индивидуальные особенности адаптации, динамика или процесс адаптации, адаптивный потенциал каждого студента $[2$, с. 6]. При этом важным диагностическим критерием должно быть наличие позитивной динамики в проявлениях всех компонентов адаптации.

\section{Организация и методики исследования}

Исследование проводилось на базе Института педагогики и психологии ФГБОУ ВО «Петрозаводский государственный университет» со студентами первых курсов. Экспериментальную группу составили иногородние студенты (26 чел.), контрольную группу - студенты, проживающие с родителями в Петрозаводске (42 чел.). Целью исследования явилось изучение трудностей адаптации у иногородних студентов. Для достижения цели применялись анкетирование «Я студент», метод ранжирования, анализ документов (медицинские карты обучающихся), методика «Шкала субъективного благополучия», t-критерий Стьюдента [3, c. 467].

\section{Гипотеза}

В основе исследования лежит предположение о том, что у иногородних студентов возникают специфические трудности адаптации, сопровождающиеся проявлениями субъективного неблагополучия (неудовлетворенность собой, переживание одиночества, пессимизм и др.).

\section{Обсуждение результатов}

Количественные данные методики «Шкала субъективного благополучия» представлены в таблице 1. Математическая обработка данных общего показателя субъективного благополучия подтвердила наличие статистически значимых различий:

$$
\mathrm{t}=8.3, \mathrm{p} \leq 0,01
$$

Из данных, представленных в таблице 1, следует, что иногородние студенты в период адаптации оценивают свое благополучие ниже, чем городские студенты. Большая часть городских студентов (59\%) находится в зоне умеренного эмоционального комфорта; они в меньшей степени испытывают эмоциональные проблемы, более уверены в себе, эффективнее взаимодействуют с окружающими, устанавливают новые социальные связи. Иногородние студенты находятся в зоне умеренного благополучия (46\%) и субъективного неблагополучия (38\%), тогда как городские студенты имеют показатели 23\% и $16 \%$ соответственно. Для них характерна неудовлетворенность собой, частые изменения настроения, высокая напряженность, неуверенность в будущем. Следовательно, можно заключить, что действительно кардинальные изменения образа жизни, связанные с переездом, в период адаптации становятся дополнительным стрессогенным фактором и затрудняют процесс адаптации.

Результаты обработки анкеты показали, что общими трудностями для контрольной и экспериментальной группы испытуемых являются следующие:

1) в сфере академической адаптации: отсутствие когнитивных стратегий, соответствующих новым тре-

Таблица 1

Количественные данные методики «Шкала субъективного благополучия»

Table 1

Quantitative data of the "Subjective well-being scale" methodology

\begin{tabular}{|c|c|c|c|c|c|}
\hline \multirow[t]{2}{*}{ Выборка } & \multirow[t]{2}{*}{ Стены } & \multicolumn{2}{|c|}{$\begin{array}{c}\text { Иногородние } \\
\text { студенты }\end{array}$} & \multicolumn{2}{|c|}{$\begin{array}{c}\text { Студенты, } \\
\text { проживающие } \\
\text { в Петрозаводске (чел) }\end{array}$} \\
\hline & & кол-во (\%) & $\begin{array}{c}\text { среднее } \\
\text { значение }\end{array}$ & кол-во (\%) & $\begin{array}{l}\text { среднее } \\
\text { значение }\end{array}$ \\
\hline $\begin{array}{l}\text { субъективное } \\
\text { неблагополучие }\end{array}$ & $8-9$ & 38 & 8,7 & 16 & 8,1 \\
\hline $\begin{array}{l}\text { умеренное } \\
\text { благополучие }\end{array}$ & $4-7$ & 46 & 6,8 & 23 & 4,7 \\
\hline $\begin{array}{l}\text { умеренный } \\
\text { эмоциональный } \\
\text { комфорт }\end{array}$ & $2-3$ & 11 & 2,9 & 59 & 2,4 \\
\hline $\begin{array}{l}\text { эмоциональный } \\
\text { комфорт }\end{array}$ & 1 & 3 & 1 & 11 & 1 \\
\hline
\end{tabular}


бованиям учебной деятельности (например, «слушать, понимать и записывать одновременно», «сокращать», «правильно вести записи и выделять основное», «не отвлекаться», «выдерживать темп преподавателя», «правильно учить», «читать первоисточники» и др.);

2) в социальной сфере адаптации возникают трудности изменения «школьного» поведения; наличие стереотипов общения, поведения, деятельности, сформировавшихся в школе, препятствует принятию и воспроизведению новых требований профессорско-преподавательского состава, однокурсников («в школе было не так», «я не могу, слишком трудно», «в школе мне бы помогли», «почему я должен делать так, а не так, как я привык» и т. д.);

3) в социально-психологической сфере - трудности, связанные с кардинальным изменением социального окружения и проявляющиеся в противоречии - необходимости занять свое место в группе, стать принятым и недостаточной социально-психологической компетентностью («много новых людей», «я привык, что меня все знают, а теперь надо знакомиться», «трачу много сил, чтобы узнать однокурсников», «все разные, чего-то хотят», «я не хочу ни с кем дружить», «хочу узнать всех, но стесняюсь»);

4) в психологической - трудности, проявляющиеся в неудовлетворенности собой как студентом, подавленном настроении, отсутствии благоприятных перспектив, связанных с обучением («ничего не получается», «наверное, сделала ошибку», «стараюсь, а толку нет», «дальше будет хуже»);

5) в профессиональной сфере у обучающихся появляется неуверенность в правильности выбора специальности, учебного заведения, сомнения («надо было, не сюда идти», «я так и думала, что не понравится», «совсем не то, о чем мечтала», «с подругой надо было ехать», «не очень нравится, но что теперь сделаешь»);

6) для физиологической адаптации характерны трудности, выражающиеся преимущественно в нарушении суточной, недельной динамики работоспособности («половина пары, а я устал», «трудно, устаю», «хочу только спать» и т. д.), астенических состояниях, психосоматических симптомах, изменении привычного режима дня.

Таким образом, выявленные трудности являются закономерными реакциями студентов на ситуацию обучения и свидетельствуют о постепенно возникающих внутренних и внешних изменениях, вызываемых новыми требованиями образовательной организации.

Наряду с вышеописанными у иногородних студентов выявлены специфические трудности адаптации, которые отсутствуют у обучающихся, проживающих в Петрозаводске. Применение метода ранжирования (балльный метод) данных испытуемыми показало, что выявленные трудности имеют различные ранги, отражающие в данном случае степень тяжести переживания трудности адаптации в определенной сфере. Количественные данные представлены в таблице 2.

Как следует из данных, представленных в таблице, первое место занимают бытовые трудности, связанные с необходимостью самостоятельно вести хозяйство («трудно готовить и учиться», «никогда не думала, что на быт уходит столько времени», «не умею готовить»,
Таблица 2

Результатыранжирования трудностей адаптациии иногородних студентов

Table 2

Results of ranking of difficulties of adaptation of nonresident students

\begin{tabular}{|l|c|c|}
\multicolumn{1}{l|}{$\begin{array}{c}\text { Трудности } \\
\text { адаптации }\end{array}$} & Среднее значение & Ранг \\
\hline бытовые & 6,8 & 1 \\
\hline $\begin{array}{l}\text { социальнопсихо- } \\
\text { логические }\end{array}$ & 6,5 & 2 \\
\hline саморегуляция & 6,1 & 3 \\
\hline физиологические & 6,1 & 3 \\
\hline экономические & 5,7 & 4 \\
\hline территориальные & 5,5 & 5 \\
\hline $\begin{array}{l}\text { организация } \\
\text { досуга }\end{array}$ & 4,9 & 6 \\
\hline
\end{tabular}

Примечание: ранжирование от самого тяжелого кменее тяжелому.

«как подумаешь, что стирать надо руками, а как?», «помыться целая проблема, очередь, условия плохие», «надоело, хочу домой»);

- социально-психологические трудности, как следствие взаимодействия с соседями по комнате («дома своя комната, а здесь колхоз», «они мне не нравятся», «почему нельзя выбрать соседей», «не хотят уступать», «хочу наладить отношения, но не получается»), ощущение одиночества, преобладание пессимистических тенденций, тревожность, подавленность;

- трудности саморегуляции, связанные с отсутствием родительского контроля и выражающиеся в нарушении режима, появлении вредных привычек, отсрочивании выполнения заданий («все равно не узнают»);

Физиологические трудности, возникающие вследствие кардинальных изменений в привычном образе жизни, количественные данные в сравнении представлены в таблице 3.

76\% иногородних студентов ложатся спать после полуночи, 85\% имеют нарушение соотношения белков, углеводов и жиров в рационе питания, а также нарушение режима питания, 87\% потребляют менее литра воды в сутки, $5 \%$ ведут сидячий образ жизни, 53\% имеют недостаточную двигательную активность. Проблемы со здоровьем возникают более, чем у половины обучающихся (головные боли, давление, обморочные состояния, нарушение аппетита и сна, боли в областижелудочно-кишечного тракта);

- экономические, связанные с необходимостью рационально расходовать финансы («хочется всего, а нельзя», «много денег уходит на еду», «хочу ногти, а денег маловато»);

- территориальные, связанные с необходимостью осваивать новые территории («я боюсь сесть и уехать не туда», «вдруг заблужусь», «искала магазин целый час и заблудилась», «в корпус на Ленина зайдешь и страшно становится», «боюсь опоздать, выхожу за два часа», «хожу всегда с кем-нибудь, одна боюсь»); 
Таблица 3

Физиологические трудности адаптащчии

Table 3

Physiological difficulties of adaptation

\begin{tabular}{|l|c|c|}
\multicolumn{1}{|c|}{ Трудности } & $\begin{array}{c}\text { Иногородние } \\
\text { студенты (\%) }\end{array}$ & $\begin{array}{c}\text { Студенты, } \\
\text { проживающие } \\
\text { в Петрозаводске } \\
(\%)\end{array}$ \\
\hline $\begin{array}{l}\text { Нарушение } \\
\text { режима дня }\end{array}$ & 76 & 26 \\
\hline $\begin{array}{l}\text { Нарушение } \\
\text { соотношения } \\
\text { жиров, белков, } \\
\text { углеводов }\end{array}$ & 85 & 12 \\
\hline $\begin{array}{l}\text { Нарушение } \\
\text { питьевого } \\
\text { режима }\end{array}$ & 87 & 23 \\
\hline $\begin{array}{l}\text { Сидячий образ } \\
\text { жизни }\end{array}$ & 5 & 4 \\
\hline $\begin{array}{l}\text { Недостаточная } \\
\text { двигательная } \\
\text { активность }\end{array}$ & 53 & 11 \\
\hline $\begin{array}{l}\text { Соматические } \\
\text { симптомы }\end{array}$ & 58 & 12 \\
\hline
\end{tabular}

- организация досуга. По сравнению с местными студентами 92\% иногородних отметили отсутствие перспектив заниматься привычным хобби, спортом, искусством и т. д.

\section{Выводы}

Таким образом, гипотеза исследования подтвердилась. Наряду с общими тенденциями, у иногородних студентов возникают специфические трудности. Их возникновение определяется действием «отягчающих факторов», прежде всего разрывом прежних родственных и дружеских отношений, отсутствием эмоциональной поддержки, тяжелыми бытовыми условиям, новым соседством, новым типом поселения и др. Безусловно, у всех обучающихся первых курсов первоначально присутствует желание стать студентом, но радость от первых дней пребывания затмевается трудностями обучения, сотрудничества, что свидетельствует о том, что студенты не готовы к трудностям, не способны активизировать накопленный адаптивный потенциал, выработанные ранее адаптивные стратегии.

Данные особенности определяют содержание адаптационных мероприятий, которые ориентированы как на городских, так и на иногородних студентов. Общими адаптационными мероприятиями являются ознакомительные экскурсии по учебным корпусам, Национальной библиотеке РК, экскурсии по городу, общежитиям, воспитательное мероприятие «Моё особое призвание» (обмен опытом с выпускниками кафедры), встречи-знакомства «Здравствуйте, это мы!», горячая линия куратора, дисциплина «Научная организация труда студентов», диагностика и социально-психологические тренинги, практикумы «Наше здоровье», индивидуальные консультации, сопровождение обучающихся адаптерами, дни здоровья, информационная работа (презентации коллективов ПетрГУ, творческих, спортивных объединений Петрозаводска). На иногородних студентов ориентированы следующие мероприятия: формирование культуры быта и экономической грамотности, горячая линия куратора, сопровождение адаптерами в общежитиях, развитие самоуправления в общежитиях, организация воспитательной работы в общежитиях.

\section{Список литературы}

1. Адаптация личности в современном мире: межвузовский сборник научных трудов. - Саратов: Наука, 2011. - №3. - 110 c.

2. Мельникова Н.Н. Диагностика социально-психологической адаптации личности: учебное пособие / Н.Н. Мельникова. - Челябинск: Изд-во ЮУрГУ, 2004. - 57 с.

3. Фетискин Н.П. Социально-психологическая диагностика развития личности и малых групп / Н.П. Фетискин, В.В. Козлов, Г.М. Мануйлов. - М.: Издво Института Психотерапии, 2002. - 488 с.

4. Шабанов Л.В. Социальная адаптация личности: методология психологического исследования / Л.В. Шабанов, И.Л. Шелехов, Е.В. Мороденко // Теоретическая и экспериментальная психология. - 2011. - Т. 4. - №3. - С. 74 -79.

\section{References:}

1. (2011). Adaptatsiia lichnosti v sovremennom mire., 3, 110. Saratov: Nauka.

2. Mel'nikova, N.N. (2004). Diagnostika sotsial'no-psikhologicheskoi adaptatsii lichnosti: uchebnoe posobie., 57. Cheliabinsk: Izd-vo IuUrGU.

3. Fetiskin, N.P., Kozlov, V.V., \& Manuilov, G.M. (2002). Sotsial'nopsikhologicheskaia diagnostika razvitiia lichnosti i malykh grupp., 488. M.: Izd-vo Instituta Psikhoterapii.

4. Shabanov, L.V., Shelekhov, I.L., \& Morodenko, E.V. (2011). Sotsial'naia adaptatsiia lichnosti: metodologiia psikhologicheskogo issledovaniia. Teoreticheskaia i eksperimental'naia psikhologiia, T. 4, 3, 74-79. 
Информация об авторах

Боденова Ольга Викторовна -

старший преподаватель Института педагогики и психологии ФГБОУ

ВО «Петрозаводский государствен-

ный университет»,

Петрозаводск, Российская

Федерация.

Власова Людмила Павловна -

канд. биол. наук, доцент ФГБОУ

ВО «Петрозаводский государствен-

ный университет»,

Петрозаводск, Российская

Федерация.
Information about the authors

Olga V. Bodenova - senior lecturer of Institute of Pedagogy and Psychology FSBEI of HE

"Petrozavodsk state University", Petrozavodsk, Russian Federation. Lyudmila P. Vlasova - candidate of biological sciences, associate professor of FSBEI of HE

"Petrozavodsk state University", Petrozavodsk, Russian Federation.
Авторсём съинчен пёлтерни Боденова Ольга Викторовна педагогика тата психологи институчӗн AB «Петрозаводск патшалӑх университечё» ФПБВУ аслӑ преподавателеу,

Петрозаводск, Рас̧сей Федерацийӗ. Власова Людмила Павловна биологи ӑслалахӗн к-чӗ, АВ «Петрозаводск патшалӑх университечё» ФПБВУ доценчӗ, Петрозаводск, Рас̧с̧ей Федерацийӗ. 